\title{
PENGEMBANGAN MODUL PEMBELAJARAN MODEL KOOPERATIF TIPE JIGSAW PADA MATAKULIAH TEKNOLOGI PROSES FABRIKASI
}

\section{DEVELOPMENT OF COOPERATIVE MODEL OF JIGSAW TYPE MODEL LEARNING IN TECHNOLOGY MATERIAL FABRICATION PROCESS}

\author{
BulkiaRahim $^{(1)}$, Suparno ${ }^{(2)}$. Nelvi Erizon ${ }^{(3)}$. Budi Syahri ${ }^{(4)}$ \\ Jurusan Teknik Mesin, Fakultas Teknik, Universitas Negeri Padang \\ Kampus Air Tawar, Padang 25131, Indonesia \\ bulkiarahim@gmail.com \\ suparno121251@gmail.com \\ nelvi erizon@yahoo.com \\ budisyahri@ft.unp.ac.id
}

\begin{abstract}
Abstrak
Berdasarkan observasi, yang menjadi permasalahan yaitu: terbatasnya buku dan modul Teknologi Proses Fabrikasi sehingga menyebabkan proses pembelajaran belum maksimal sehingga mempengarui hasil belajar. Selain dari keterbatasan modul juga terdapat belum terarahnya materi pembelajaran dengan synopsis pembelajaran Teknologi Proses Fabrikasi. Tujuan penelitian untuk menghasilkan modul Teknologi Proses Fabrikasi berbasismodelkooperatif tipe jigsaw yang valid, praktis dan efektif agar layak digunakan dalam pembelajaran dan sesuai dengan perkembangan teknologi pada saat ini. Model penelitian yang digunakan adalah eksperimen. Dengan metode penelitian dan pengembangan (Research and Development $/ R \& D$ ). Subjek penelitian adalah mahasiswa Teknik Mesin FT-UNP yang mengambil mata kuliah Teknologi Proses Fabrikasi. Jenis data yaitu data primer dimana data yang diberikan oleh dosen ahli dan mahasiswa.Instrumen pengumpul data berbentuk angket. Teknik analisis data deskriptif untuk mendeskripsikan kevalidan, kepraktisan dan keefektifan modul Teknologi Proses Fabrikasiberbasismodelkooperatif tipe jigsaw. Hasil yang diperoleh dari penelitian eksperimen ini adalah menghasilkan sebuah modul Teknologi Proses Fabrikasi berbasismodelkooperatif tipe jigsawyang valid, praktis dan efektif di dalam Teknologi Proses Fabrikasi.
\end{abstract}

Kata Kunci: Modul, Teknologi Proses Fabrikasi, Hasil Belajar, Kooperativ Tipe Jigsaw dan Research and Development.

\begin{abstract}
Based on observations, the problem is: the limited books and modules of the Fabrication Process technology, causing the learning process to be not maximal so that it affects learning outcomes. Apart from the limitations of the module there are also no directional learning materials with the synopsis of learning about Fabrication Process Technology. The research objective is to produce a Fabrication Process Technology module based on a jigsaw type cooperative model that is valid, practical and effective so that it is suitable for use in learning and in accordance with current technological developments. The research model used was an experiment. With research and development $(R \& D)$ methods. The research subjects were the Mechanical Engineering students of the FT-UNP who took the Fabrication Process Technology course. Type of data is primary data where data is provided by expert lecturers and students. The instrument for collecting data is in the form of a questionnaire. Descriptive data analysis techniques to describe the validity, practicality and effectiveness of the Fabrication Process Technology module based on the jigsaw type cooperative model. The results obtained from this experimental study are to produce a Fabrication Process Technology module based on a jigsaw type cooperative model that is valid, practical and effective in the Fabrication Process Technology.

Keywords: Modules, Fabrication Technology Processes, Learning Outcomes, Cooperative Jigsaw Types and Research and Development.
\end{abstract}




\section{Pendahuluan}

Belajar adalah sebuah proses perubahan tingkah laku sebagai hasil dari interaksinya terhadap lingkungan dalam memnehi kebutuhannya (Sugihartono:2007).

Pembelajaran merupakan uapaya yang dilakukan oleh pendidikan dengan unsur sengaja yang dapat mengakibatkan proses dalam sebuah kegiatan belajara (Sudjana dalam Sugihartono:2007).

Modul merupakan sesuatu unitayang lengkapayangaberdiriasenidriadan terdiri atasarangkaianakegiatanabelajar yang disusun untukmencapai tujuanyangditetapkansecarakhusus dan jelasa(Nasutionadalalm buku Suparno:2017).

Proses belajar mengajar pada hakikatnya adalah praktek komunikasi dimana praktek antara sumber pesan ke penerima pesan. Kualitas suatu pendidikan dalam sebuah sekolah ditentukan oleh kualitas dalam sebuah proses pembelajaran. Dari setiap banyak unsur sarana pendidikan yang ada disekolah yang sangat menentukan adalah kualitas buku pelajaran yang ada disekolah. Karna kenyataannya buku pelajaran adalah jantung pembelajaran.

Faktor lain yang juga akan menjadi kualitas

Proses pembelajaran mata kuliah Teknologi Proses Fabrikasi masih metode ceramah. Penyampaian materi di dalam pembelajaran yang kurang tepat dan pemilihan media pembelajaran maka akan berdampak kepada pemahaman mahasiswa di dalam memahami materi pembelajaran (Suparno: 2018 ). Maka perlu memilih media pembelajaran yang tepat untuk intraksi antara siswa dengan dosen untuk dapat menigkatkan penyerapan materi oleh mahasiswa (Suparno:2018).

Kurangnya bahan ajar atau sumber pembelajaran merupakan salah satu bagian penyebab dari tidak maksimalnya dari pemahaman mahasiswa di dalam pembelajaran mata kuliah Teknologi Proses Fabrikasi. Untuk itu perlu menambah referensi dan memperbanyak bahan ajar Teknologi Proses Fabrikasiuntuk menunjang kemampuan mahasiswa di dalam memahami pelajaran.

Hasil dari nilaiSemester Juli-Desember 2018, kompetensi mahasiswa yang dicapai juga masih belum maksimal.
Tabel 1.1. Nilai Semester Matakuliah Teknologi Proses Fabrikasi Semester JuliDesember 2018

\begin{tabular}{|c|c|c|c|c|}
\hline \multirow[b]{2}{*}{$\mathrm{p}$} & \multirow{2}{*}{$\begin{array}{c}\text { Kode } \\
\text { Seksi } \\
\text { Interval } \\
\text { Nilai } \\
\text { Angka } \\
\end{array}$} & \multicolumn{3}{|c|}{$\begin{array}{l}\text { Seksi } 201810720074 \text { dan seksi } \\
201810720075\end{array}$} \\
\hline & & $\begin{array}{c}\text { Interval } \\
\text { Nilai Huruf } \\
\end{array}$ & $\begin{array}{l}\text { Frekuensi } \\
\text { (f) }\end{array}$ & $\begin{array}{l}\text { Persentase } \\
(\%)\end{array}$ \\
\hline 1 & $0-39$ & $\mathrm{E}$ & 4 & 5.88 \\
\hline 2 & $40-49$ & $\mathrm{D}$ & 3 & 4.41 \\
\hline 3 & $50-54$ & $\mathrm{C}-$ & 1 & 1.47 \\
\hline 4 & $55-69$ & $\mathrm{C}$ & 5 & 7.35 \\
\hline 5 & $60-64$ & $\mathrm{C}+$ & 6 & 8.82 \\
\hline 6 & $65-69$ & B- & 12 & 17.65 \\
\hline 7 & $70-74$ & $\mathrm{~B}$ & 13 & 19.12 \\
\hline 8 & $75-79$ & $\mathrm{~B}+$ & 11 & 16.18 \\
\hline 9 & $80-84$ & A- & 6 & 8.82 \\
\hline 10 & $\begin{array}{c}85- \\
100 \\
\end{array}$ & A & 7 & 10.29 \\
\hline \multicolumn{3}{|c|}{ Jumlah } & 68 & 100.00 \\
\hline \multicolumn{3}{|c|}{$\begin{array}{l}\text { Nilai Kecil 64, Nilai } \\
\text { dibawah B- }\end{array}$} & 19 & 27.94 \\
\hline \multicolumn{3}{|c|}{$\begin{array}{c}\text { Nilai Besar 65, Nilai diatas } \\
\mathrm{C}+\end{array}$} & 49 & 72.06 \\
\hline
\end{tabular}

Sumber : http://sia.unp.ac.id

Modul pada mata kuliah Teknologi Proses Fabrikasi ini belum ada sebelumnya. Jurusan Teknik Mesin hanya terdapat Perangkat pembelajaran Teknologi Proses Fabrikasi dan berbagai macam buku tentang Teknologi Proses Fabrikasi yang ada di perpustakaan Jurusan Teknik Mesin. Hal ini membuat mahasiswa kurang belajar mandiri.

Mengatasi permasalahan tersebut di atas maka perlunya menambah referensi di dalam pembelajaran mahasiswa seperti modul sebagai media pembelajaran. Modul memiliki kelebihankelebihan untuk pembelajaran karna di dalam modul tersdiri dari: 1). Pedoman 2). Lembaran kegiatan mahasiswa. 3). Lembaran kerja. 4). Tes Pemahaman materi pembelajaran. 5). Kunci lembaran tes. Sehingga dengan terstukturnya pembelajaran baik materi maupun langkah kerja mahasiswa di dalam modul maka di harapkan akan membawa dampak terhadap pemahaman mahasiswa di dalam pembelajaran (Bulkia Rahim : 2017). Maka modul sangat penting di dalam pembelajaran Teknik Pemesinan dan Fabrikasi.

Permasalahan media pembelajaran yang belum maksimal maka diupayakan untuk mencoba mengembangkan modul pembelajaran pada mata kuliah Teknologi Proses Fabrikasi. Sudah adanya perangkat pembelajaran Teknologi Proses Fabrikasi, buku Teknologi Proses Fabrikasi di 
Jurusan Teknik Mesin FT-UNP maka perlu dilakukannya pengembangan berbentuk modul.

Modul Teknologi Proses Fabrikasi model koopertaif tipe jigsaw diharapkan mahasiswa dapat belajar mandiri dan belajar berkelompok serta dapat lebih semangat karena modul Teknologi Proses Fabrikasi model koopertaif tipe jigsaw memberikan fasilitas kepada mahasiswa di dalam memahami materi pembelajaran. KooperatifTipeJigsaw bertujuan untuk meningkatkan pemahaman dan hasil belajar di dalam pembelajaran (Bulkia Rahim : 2018).

Rumusan masalah pada penelitian ini adalah sebagai berikut:

1. Bagaimanakah Validitas, Praktikalitas dan Efektifitas modul Teknologi Proses Fabrikasi model kooperatif Tipe jigsaw?

2. Apakah ada perbedaan hasil belajar kelas eksperimen yang menggunakan modul Teknologi Proses Fabrikasi model koopertaif tipe jigsaw dengan kelas control yang tidak menggunakan modul?

\section{Metode Penelitian}

Penelitian ini menggunakan metode penelitian dan pengembangan (Research and Development). Penelitian dan pengembangan adalah rangkaian proses atau langkah-langkah dalam rangka mengembangkan suatu produk baru atau menyempurnakan produk yang telah ada agar dapat dipertanggungjawabkan (Trianto : 2012 ). Penelitian pengembangan adalah metode penelitian yang digunakan untuk menghasilkan produk tertentu dan menguji keefektifan produk tersebut. Penelitian dan pengembangan dalam pendidikan adalah proses yang digunakan untuk mengembangkan dan memvalidasi produk pendidikan (Sugiyono : 2011).

Penelitian dilakukan pada mahasiswa tingkat 4 Jurusan Tenik Mesin Fakultas Teknik Universitas Negari Padang.Penelitian dilakukan pada semester Juli - Desember 2019.

Subjekpada penelitian ini adalah mahasiswa kelas Teknologi Proses Fabrikasi Jurusan Teknik Mesin Jenis data adalah data primer merupakan data yang diperoleh secara langsung dari mahasiswa yang diambil melalui angket.

Instrumen pengumpul data adalah alat bantu yang digunakan untuk mengumpulkan data agar kegiatan tersebut menjadi sistematis dan mudah.

\section{III.Hasil Penelitian}

Penelitian ini menghasilkan suatu produk modul Teknologi Proses Fabrikasi model koopertaif tipe jigsaw. Adapun rincian modul Teknologi Proses Fabrikasi model koopertaif tipe jigsaw yang dihasilkan adalah terdiri atas komponenkomponen sebagai berikut:

a. Modul Teknologi Proses Fabrikasi model koopertaif tipe jigsawterdiri dari modul kegiatan kuliah 1. Mengidentifikasi Ruang Lingkup Pekerjaan Fabrikasi 2. Keselamatan Kerja Pada Teknik Fabrikasi 3. Pengetahuan Bahan Pada Teknik Fabrikasi 4. Fungsi Gambar Teknik Pada Pekerjaan Fabrikasi 5. Fungsi Alat Ukur dan Penandaan Pada Teknik Fabrikasi 6. Perkakas Tangan Dalam Pembentukan Pada Teknik Fabrikasi 7. Metode Pemotongan Pada Teknik Fabrikasi 8. Proses Pemebentukan Plat Pada Pekerjaan Fabrikasi 9. Proses Perakitan Pada Teknik Proses Fabrikasi 10. Teknik Dan Prosedur Penyambungan Logam/Las Busur Listrik Pada Teknik Fabrikasi 11. Proses Pengelasan Oxy Asitelin Pada Teknik Fabrikasi 12. Proses Pengelasan TIG Pada Teknik Fabrikasi 13. Proses Pengelasan MIG Pada Teknik Fabrikasi 14. Proses Pengerjaan Tempa Pada Teknik Fabrikasi

b. Modul kegiatan kuliah 1 sampai kegiatan kuliah 8 mempunyai 14 kegiatan kuliah. Masing-masingkegiatan kuliah terdiri dari indikator tujuan kegiatan perkuliahan, uraian materi, rangkuman, tes formatif, soal latihan, lembaran kerja mahasiswa dan jawaban tes formatif.

c. Latihan pada setiap kegiatan kuliah terdiri atas latihan tes formatif dengan jumlah soal sebanyak 5 butir untuk soal objebtif dan 5 butir soal essay.

\section{Data Uji Validitas}

Pengambilan data validitas modul Teknologi Proses Fabrikasi model koopertaif tipe jigsawsebagai modul pembelajaran adalah dengan menggunakan angket (kuesioner). Dalam hal ini peneliti memberikan angket kepada tiga orang validator yang memvalidasi modul yang dikembangkan. Validator pertama, ke dua, ke tiga, validasi serta penilaian terhadap materi, validasi terhadap format dan penyajian pada modul yang dikembangkan.

Hasil penilaian dari masing-masing aspek indikator yang diberikan validator dijumlahkan dan dihitung persentase penilaian menurut aspek yang telah dibuat. Berikut deskripsi data yang didapat pada penelitian ini: 


\section{a. Data Uji Validasi Isi/Materi}

Penilaian validator tentang kevalidan isi/materi modul Teknologi Proses Fabrikasi model koopertaif tipe jigsawteridiri dari 3 orang dosen Jurusan Teknik Mesin FT-UNP dapat dilihat pada tabel 2 berikut:

Tabel 2. Penilaian Validator Tentang Kevalidan Isi/Materi ModulTeknologi Proses Fabrikasi Model Koopertaif Tipe Jigsaw

\begin{tabular}{|c|c|c|c|c|c|c|c|c|c|c|c|c|}
\hline \multicolumn{13}{|c|}{ Data Validitas Materi Modul Teknologi Proses Fabrikasi Model Koopertaif Tipe Jigsaw } \\
\hline \multirow[b]{3}{*}{ No } & \multirow{3}{*}{ Validator } & \multicolumn{9}{|c|}{ Item Peryantaan Angket } & \multirow{3}{*}{$\begin{array}{l}\text { Hasil } \\
\text { Validasi }\end{array}$} & \multirow{3}{*}{ Kategori } \\
\hline & & \multicolumn{4}{|c|}{ Kualitas Isi } & \multicolumn{5}{|c|}{ Kualitas Pembelajaran } & & \\
\hline & & 1 & 2 & 3 & 4 & 5 & 6 & 7 & 8 & 9 & & \\
\hline 1 & 1 & 5 & 4 & 5 & 4 & 5 & 4 & 4 & 5 & 5 & 0.89 & Valid \\
\hline 2 & 2 & 4 & 5 & 4 & 5 & 4 & 4 & 4 & 5 & 4 & 0.83 & Valid \\
\hline 3 & 3 & 5 & 5 & 5 & 4 & 5 & 5 & 4 & 5 & 5 & 0.94 & Valid \\
\hline \multicolumn{11}{|c|}{ Nilai Rata-rata Hasil Validasi } & $\mathbf{0 , 8 9}$ & Valid \\
\hline
\end{tabular}

Tabel 2. dapat disimpulkan bahwa penilaian data validasi materimodul Teknologi Proses Fabrikasi model koopertaif tipe jigsawdiatas diisi oleh ahli materi yaitu dosen Fakultas Teknik Jurusan Teknik Mesin yang mengampu mata kuliah Teknologi Proses Fabrikasi, ke tiga validator didapat kevalidan materi/isi pada modul
Teknologi Proses Fabrikasi model koopertaif tipe jigsawadalah 0,89 dengan kategori “valid".

\section{b. Data Uji Validasi Format Modul}

Penilaian validator tentang kevalidan format modul Teknologi Proses Fabrikasi model koopertaif tipe jigsawdapat dilihat pada Tabel3.berikut:

Tabel 3. Penilaian Validator Tentang Kevalidan Format Modul Teknologi Proses Fabrikasi Model Koopertaif Tipe Jigsaw

\begin{tabular}{|c|c|c|c|c|c|c|c|c|c|c|c|c|c|c|c|c|}
\hline \multicolumn{17}{|c|}{ Data Validitas Format Modul Teknologi Proses Fabrikasi Model Koopertaif Tipe Jigsaw } \\
\hline \multirow[t]{3}{*}{ No } & \multirow[t]{3}{*}{ Validator } & \multicolumn{13}{|c|}{ Item Peryantaan Angket } & \multirow{3}{*}{$\begin{array}{c}\text { Hasil } \\
\text { Validasi }\end{array}$} & \multirow{3}{*}{ Kategori } \\
\hline & & \multicolumn{8}{|c|}{ Aspek Format } & \multicolumn{5}{|c|}{ Aspek Bahasa } & & \\
\hline & & 1 & 2 & 3 & 4 & 5 & 6 & 7 & 8 & 1 & 2 & 3 & 4 & 5 & & \\
\hline 1 & 1 & 5 & 5 & 4 & 5 & 5 & 4 & 5 & $5 \mid 2$ & 5 & 5 & 4 & 5 & 4 & 0.88 & Valid \\
\hline 2 & 2 & 5 & 4 & 5 & 5 & 4 & 5 & 5 & 45 & 5 & 4 & 5 & 4 & 5 & 0.86 & Valid \\
\hline 3 & 3 & 5 & 5 & 4 & 5 & 4 & 4 & 5 & \begin{tabular}{l|l}
5 & 4 \\
\end{tabular} & 5 & 5 & 4 & 5 & 4 & 0.88 & Valid \\
\hline & & & ilai & Rat & a-ra & t & Tasi & $\mathbf{V a}$ & idas & & & & & & 0.87 & Valid \\
\hline
\end{tabular}

Tabel 3. dapat disimpulkan bahwa data validasi format modul Teknologi Proses Fabrikasi model koopertaif tipe jigsawdiatas diisi oleh tiga orang validator yang mengampu mata kuliah Teknologi Proses Fabrikasi didapat hasil validasi penyajian 0,87 dengan kategori "Valid".

\section{c. Data Uji Validasi Penyajian Modul}

Penilaian validator tentang kevalidan format modul Teknologi Proses Fabrikasi model koopertaif tipe jigsawdapat dilihat pada tabel 4.berikut: 
Tabel 4. Penilaian Validator Tentang Kevalidan Penyajian modul Teknologi Proses Fabrikasi Model Koopertaif Tipe Jigsaw

\begin{tabular}{|c|c|c|c|c|c|c|c|c|c|c|c|c|c|c|c|c|c|}
\hline \multicolumn{18}{|c|}{ Data Validitas Penyajian Modul Teknologi Proses Fabrikasi Model Koopertaif Tipe Jigsaw } \\
\hline \multirow{3}{*}{ No } & \multirow{3}{*}{ Validator } & \multicolumn{14}{|c|}{\begin{tabular}{|l|} 
Item Peryantaan Angket \\
\end{tabular}} & \multirow{3}{*}{$\begin{array}{c}\text { Hasil } \\
\text { Validasi }\end{array}$} & \multirow{3}{*}{ Kategori } \\
\hline & & \multicolumn{4}{|c|}{ Isi } & \multicolumn{2}{|c|}{$\begin{array}{c}\text { Gam } \\
\text { bar }\end{array}$} & \multicolumn{5}{|c|}{ Bahasa } & \multicolumn{3}{|c|}{ Tampilan } & & \\
\hline & & 1 & 2 & 3 & 4 & 1 & 2 & 1 & 2 & 3 & 4 & 5 & 1 & 2 & 3 & & \\
\hline 1 & 1 & 5 & 5 & 4 & 5 & 4 & 5 & 5 & 4 & 5 & 4 & 5 & 4 & 4 & 5 & 0.89 & Valid \\
\hline 2 & 2 & 4 & 4 & 4 & 4 & 5 & 5 & 5 & 4 & 5 & 5 & 4 & 5 & 5 & 4 & 0.88 & Valid \\
\hline 3 & 3 & 4 & 5 & 5 & 5 & 4 & 4 & 5 & \begin{tabular}{l|l}
4 \\
\end{tabular} & 5 & 4 & 5 & 5 & 5 & 5 & 0.91 & Valid \\
\hline \multicolumn{16}{|c|}{ Nilai Rata-rata Hasil Validasi } & 0.89 & Valid \\
\hline
\end{tabular}

Dari tabel 4 dapat disimpulkan bahwa data validasi penyajian modul Teknologi Proses Fabrikasi Model Koopertaif Tipe Jigsawdiatas diisi oleh tiga orang validator yang mengampu mata kuliah Teknologi Proses Fabrikasi didapat hasil validasi penyajian 0,89 dengan kategori "Valid".

Dari keseluruhan nilai validasi yang diberikan oleh masing-masing validator berturut-turut nilai

validasi isi/materi sebesar 0,89 dengan kategori "valid", nilai validasi format modul sebesar 0,87 dengan kategori "valid", nilai validasi penyajian modul sebesar 0,89 dengan kategori "valid". Dapat diambil rata-rata validasi modul Teknologi Proses Fabrikasi Model Koopertaif Tipe Jigsaw yaitu 0,88 sehingga dapat disimpulkan modul tersebut masuk pada kategori "Valid". Sebagaimana terlihat pada tabel 5.berikut:

Tabel 5. Hasil Keseluruhan Validasi modul Teknologi Proses Fabrikasi Model Koopertaif Tipe Jigsaw

\begin{tabular}{|c|c|c|c|}
\hline No & Data Validitas Modul Berbasis Kooperatif Model Jigsaw & $\begin{array}{l}\text { Nilai Rata- } \\
\text { rata \% }\end{array}$ & Kategori \\
\hline 1 & $\begin{array}{l}\text { Validitas Materi Modul Teknologi Proses Fabrikasi Model } \\
\text { Koopertaif Tipe Jigsaw }\end{array}$ & 0.89 & Sangat Valid \\
\hline 2 & $\begin{array}{l}\text { Validitas Format Modul Teknologi Proses Fabrikasi Model } \\
\text { Koopertaif Tipe Jigsaw }\end{array}$ & 0.87 & Sangat Valid \\
\hline 3 & $\begin{array}{l}\text { Validitas Penyajian Modul Teknologi Proses Fabrikasi Model } \\
\text { Koopertaif Tipe Jigsaw }\end{array}$ & 0.89 & Sangat Valid \\
\hline \multicolumn{2}{|r|}{$\begin{array}{c}\text { Nilai Rata-rata Validitas Modul Teknologi Proses Fabrikasi Model } \\
\text { Koopertaif Tipe Jigsaw }\end{array}$} & 0.88 & $\begin{array}{l}\text { Sangat } \\
\text { Valid }\end{array}$ \\
\hline
\end{tabular}

\section{Kesimpulan}

Berdasarkan hasil penelitian pengembangan modul yang telah dilakukan, maka diperoleh kesimpulan sebagai berikut:

1. Penelitian pengembangan modul Teknologi Proses Fabrikasi Model Koopertaif Tipe Jigsaw terdiri dari 8 kegiatan kuliah yang disesuaikan dengan sinopsis dan SAP Tata Teknologi Proses Fabrikasi. Masing-masing kegiatan kuliah terdiri dari indikator tujuan kegiatan perkuliahan, uraian materi, rangkuman, tes formatif, soal latihan, lembaran kerja mahasiswa dan jawaban tes formatif. Latihan pada setiap kegiatan kuliah terdiri atas latihan tes formatif dengan jumlah soal sebanyak 5 butir untuk soal objebtif dan 5 butir soal essay.

2. Validitas modul Teknologi Proses Fabrikasi Model Koopertaif Tipe Jigsaw pada aspek materi di dalam modul di dapat rata-rata hasil validasi adalah 0,89 dengan kategori "valid", pada aspek format didalam modul di dapat rata-rata hasil validasi adalah 0,87 dengan kategori "valid", pada aspek penyajian didalam modul di dapat rata-rata hasil validasi adalah 0,89 dengan kategori "valid", Rata-rata hasil modul Teknologi Proses Fabrikasi Model 
Koopertaif Tipe Jigsawyaitu 0,88 sehingga dapat disimpulkan modul tersebut masuk pada kategori "Valid". Praktikalitas modul dalam pembelajaran dapat dilihat dari keterlaksanaan

\section{Referensi}

Bulkia Rahim. 2018. Pengembangan Perangkat Pembelajaran Berbasis Model PJBL Pada Mata Diklat Teknik Digital. Jurnal Pendidikan Teknologi Kejuruan 1 (3), 133-142.

BulkiaaRahim dkk. (2018). Validitas Modul Pembelajaran Model Kooperatif Tipe Jigsaw PadaaMata Pelajaran Teknik FabrikasiaVol 1, No. 2.

Lie, Anita. 2002. Kooperatif : mempraktikkan kooperatif diruang-ruang kelas, Jakarta: Grasindo

NelviaErizon dkk. (2019). Efektivitas Tugas Dosen PenasehataAkdemik dengan DiberlakukanyaaSistem KRS Online pada MahasiswaaJurusan Teknik Mesin FT UNP Vol 1, No. 1.

Sugiyono. (2006). Metode Penelitian Administrasi..aBandung: Alfabeta.

Sugiyono. 2011. Metode Penelitian Kuantitatif, Kualitatif dan R\&D. Bandung: Alfabeta.

Suharsimi Arikunto. (2002). Metodologi Penelitian. Jakarta: PT. Rineka Cipta.

Suparno. 2018. The Influence of Cooperative Learning Jigsaw Model and Learning Module on Learning Outcomes in vocational education. The International Conference on Aptekindo "Revitalization of Technical and Vocational Education to Face Industrial Revolution 4.0

Suparno. 2018. Validitas Modul Pembelajaran Model Kooperatif Tipe Jigsaw Pada Mata Kuliah Teori Teknik Fabrikasi. Jurnal Pendidikan Teknologi Kejuruan.

Trianto. 2012. Mendesain Model Pembelajaran Inovatif-Progresif. Jakarta: Kencana Predana Media Group. penggunaan modul Teknologi Proses Fabrikasi Model Koopertaif Tipe Jigsaw secara keseluruhan dengan baik. 